\title{
EL ESPACIO Y EL TIEMPO TEATRALES: PROPUESTA DE ACERCAMIENTO SEMIÓTICO
}

\author{
Fabián Gutiérrez Flórez \\ Universidad de Valladolid
}

\section{FUNDAMENTOS TEÓRICOS OPERATIVOS.}

\subsection{La dicotomía texto/representación.}

El teatro es potencia y acto, previsión textual y plasmación escénica, género literario y producto semiótico privilegiado en la representación de unos hechos imbricados en una acción, por unos actores o actrices, en un espacio concreto, durante un tiempo limitado, para que pueda ser contemplada por los espectadores que asisten a su desarrollo.

Entendemos, pues, el teatro como la fusión, en permanente interacción, de los dos aspectos citados: el teatro es tanto un género literario cuyo fin es la representación de su texto, como la propia representación del texto sobre un escenario !.

1.- Esta dicotomía ha sido tenida en cuenta desde siempre por los teóricos del teatro, aunque en determinados momentos histórico-literarios haya sido preferido uno u otro de los aspectos. Ya Aristóteles decía en su Poética que el más importante de los elementos de la tragedia era la fábula, o «estructuración de los hechos" (1450a), y que «el espectáculo, en cambio, es cosa seductora, pero muy ajena al arte y la menos propia de la poética (...). Además, para el montaje de los espectáculos es más valioso el arte del que fabrica los trastos que el de los poetas» (1450b), (pp. 147 y 151 de la edición trilingüe de Valentín García Yebra, Madrid, Gredos, 1974). Vid. Alonso López Pinciano, Philosophía Antigua Poética, 1596 (ed. de Alfredo Carballo Picazo, Madrid, CSIC, 1953, pp. 276277), donde distingue en el teatro («poema activo»), el texto de la representación. Cfr. Manuel Sito Alba, Introducción al estudio semiótico del teatro, Madrid, UNED (apuntes para curso), 1985, pp. 54-56 (editado como Análisis de la Semiótica teatral, Madrid, UNED, 1987). 


\section{FABIÁN GUTIÉRREZ FLÓREZ}

Así, podemos hablar del teatro, del shecho teatral», como de un conjunto de elementos cuya combinación es heterogénea (aunque tales elementos presenten homogeneidad al ser agrupados en sistemas o códigos), en el que pueden detectarse dos fases: la textual y la espectacular (nacidas respectivamente de sus dos componentes básicos citados: el literario - texto - y el espectacular —representación- - $)^{2}$.

Sin embargo, esta dicotomía no supone oposición, porque como señala A. Serpieri, el sentido de la escena es el sentido del texto y las formas de la escena no son más que el desarrollo de las indicaciones contenidas en el texto ${ }^{3}$. En consecuencia, sin sacralizar el componente textual ha de reconocerse lo evidente: la facilidad de acceso al texto dramático (que precede y sobrevive a la representación), por un lado y, por otro, la potencial rentabilidad analítica que ofrece a quien desee analizar semióticamente el teatro, puesto que, en definitiva, el texto contiene ya virtualmente su propia representación ${ }^{4}$.

\subsection{La dicotomía diegético/mimético.}

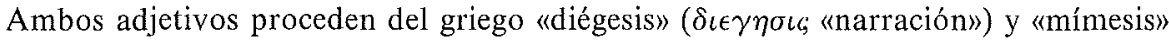

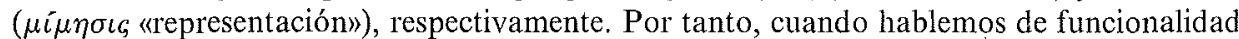
diegética nos referiremos a la que cumplen los elementos del hecho teatral en cuanto componentes del relato que toda obra dramática suele contener; y cuando hagamos referencia a su funcionalidad mimética queremos con ello aludir a la que desempeñan tales elementos como específicamente teatrales, como portadores y sustentadores de la «dramaticidad» de la obra en que están operando ${ }^{5}$.

2.- Vid. nuestro artículo «Aspectos del análisis semiótico teatral» en Castilla, 14, 1989, pp. 80-83, donde desarrollamos la concepción del hecho teatral como un proceso acumulativo de componentes humanos y elementos-signo diversos, que puede ser descompuesto en siete momentos, desde la concepción de la obra dramática por el autor hasta su recepción por el espectador.

3.- Vid. Alessandro Serpieri, «Toward a Segmentation of the Dramatic Text», en Poetics Today, 2, 3, 1981, pp. 156 y ss., así como «Ipotesi teorica di segmentazione del testo teatrale», en A. Serpieri y otros, Come communica el teatro: del testo alla scena. Milán, Il Formichiere, 1978, pp. 99-135.

4.- Cfr. María del Carmen Bobes Naves, Semiología de la obra dramática, Madrid, Taurus, 1987, pp. 30-32; Anne Ubersfeld, Lire le theâtre, París, Editions Sociales, 1978, pp. 15-25 (hay traducción española de Francisco Torres Monreal, Semiótica teatral, Madrid, Cátedra/Universidad de Murcia, 1989); Jorge Urrutia, «De la posible imposibilidad de la crítica teatral y de la reivindicación del texto literarion, en José M. ${ }^{a}$ Díez Borque y Luciano García Lorenzo (editores), Semiología del teatro, Barcelona, Planeta (Ensayos/Planeta), 1975, pp. 278-279; Marco de Marinis, «Lo spettacolo come testo (I)", en Versus, 21, septiembre-diciembre 1978, pp. 67-77; José María Díez Borque, «Pórtico sencillo al teatro - del texto a la representación-», en J. M. Díez Borque (director), Historia del Teatro en España, Madrid, Taurus, 1983, pp. 20-22; Gianfranco Bettetini, «El giro pragmático de las semióticas de la representación”, en Miguel Ángel Garrido Gallardo (editor), Teoría semiótica. Lenguaje y textos hispánicos, Madrid, C.S.I.C., 1984, p. 26; de este mismo autor «Drama y puesta en escena», en Discurso, 1, Sevilla, Alfar, 1987, pp. 3-24; Franco Ruffini, «Testo/scena: drammaturgia dello spettacolo e dello spettatore», en Versus, 41, 1985, pp. 21-40; L. Allegri, «Teatro vs Espectáculo: Materiales para una oposición», en Eutopías, vol. I, 1-2, Valencia, invierno-primavera 1985, pp. 157-179; Patrice Pavis, «La recepción del texto dramático y espectacular», en Discurso, cit., pp. 30-34; y Fernando de Toro, Semiótica del teatro. Del texto a la representación, Buenos Aires, Ed. Galerna, 1987, pp. 65-68.

5.- Los términos diégesis y mímesis pueden verse ya en los preceptistas clásicos, para quienes teóricamente no eran coincidentes. Vid. Platón, La República o el Estado, Libro III, 392d y 394d, así como el Libro X (versión de Patricio Azcárate, Madrid, EDAF, 1985, pp. 116-118); y Aristóteles, Poética, 1448a (ed. cit., pp. 133-134). Cfr. Francisco Rodríguez Adrados, Fiesta, comedia .' tragedia. 


\section{EL ESPACIO Y EL TIEMPO TEATRALES}

\subsection{La tricotomía morrisiana del análisis semiótico.}

Uno de los posibles modos de acercamiento semiótico a la literatura es el que aplica la subdivisión postulada por Morris: sintáctica (estudio de las relaciones signo-signo), semántica (análisis de las relaciones signo-objeto) y pragmática (estudio de las relaciones signo-sujeto) ${ }^{6}$.

Siguiendo este esquema tripartito y aplicando al nivel sintáctico las categorías de la narratologia, en especial la de «función», proponemos al acercamiento semiótico al espacio y al tiempo teatrales?

\section{EL ESPACIO Y EL TIEMPO EN EL TEATRO.}

\subsection{El espacio.}

Al igual que la categoría «tiempo», con la que mantiene una relación estrecha, el espacio es determinante para el desarrollo de la fase espectacular del hecho teatral, lo que consecuentemente condiciona la fase textual, que ha de contemplar el funcionamiento de ambas categorías.

E1 texto teatral es concebido como un proyecto de un hic et numc, porque en la representación lo que se transmite a los espectadores es un «aquí y ahora» simulado que, igualmente, puede simular un "no aquí» y un «no ahora». Hemos de considerar, por tanto, que hay varios tipos de espacio en el teatro: en primer lugar, hay un espacio textual frente a (aunque previéndolo) un espacio espectacular, es decir, un espacio previsto en el texto dramático, y un espacio concreto y material que el espectador percibe en la representación; en segundo lugar, dentro del espacio textual hemos de distinguir un espacio «diegético» (el que corresponde a la «historia»), de un espacio «mimético» (que corresponde al «discurso»); y en tercer lugar, dentro del espacio espectacular podemos diferenciar un espacio escénico (el lugar concreto donde se representa la acción dramática), de un espacio teatral, o lugar teatral, donde se produce la relación texto-espectador (la definitiva recepción del espectáculo).

Sobre los origenes griegos del teatro, Barcelona, Planeta, 1972, p. 52; Patrice Pavis, Diccionario del teatro. Dramaturgia, estética, semiología, Barcelona, Paidós, 1984, p. 311; Cesare Segre, Principios de análisis del texto literario, Barcelona, Ed. Crítica -Grupo editorial Grijalbo-, 1985, p. 22, para quien «de forma mucho más general, se puede decir que mímesis equivale a teatro o representación análoga, diégesis a narración»; y Gérard Genette, "Géneros, 'tipos', modos», en Miguel Angel Garrido Gallardo (compilador), Teoría de los géneros literarios, Madrid, Arco/Libros, 1988, pp. 188 y 190. 6.- Vid. Charles Morris, Writings on the General Theory of Signs, La Haya, Mouton, 1971, pp. 2123 y 63-69. Cfr. Francesco Casetti, Introducción a la semiótica, Barcelona, Fontanella, 1980, p. 146; Tzvetan Todorov, Gramática del Decamerón, Madrid, Taller de Ediciones, 1973; Jenaro Talens y otros, Elementos para una semiótica del texto artístico, Madrid, Cátedra, 1978, p. 47; y José Romera Castillo, El comentario semiótico de textos, Madrid, S.G.E.L., 1980, pp. 63-71.

7.- Vid. Roland Barthes, «Introducción al análisis estructural de los relatos», en R. Barthes y otros, Análisis estructural del relato, Barcelona, Ed. Buenos Aires, 1982, pp. 17-22, donde clasifica las funciones en: a) distribucionales, funciones propiamente dichas (cardinales y catálisis o secundarias), y b) integrativas, indicios (indicios propiamente dichos e informaciones), al tiempo que precisa sobre las últimas que «sirven para identificar, para situar en el tiempo y en el espaciom, y que no tienen significados implícitos, al menos a nivel de la historia, porque son datos puros, inmediatamente significantes, que proporcionan un conocimiento elaborado. 


\section{FABIÁN GUTIÉRREZ FLÓREZ}

Fxaminaremos brevemente estos diversos tipos de espacio aislables en el hecho teatral, así como las relaciones que mantienen entre sí y con el espacio (mundo) real.

El espacio es en el teatro un espacio artístico, porque el teatro es una obra de arte tanto verbal como espectacular, y porque como tal obra de arte crea, delimita y produce en su finitud un objeto infinito: el mundo exterior respecto a la obra. De este modo, dice Aleksandrov, la estructura del espacio del texto se convierte en modelo de la estructura del espacio del universo, y la sintagmática de los elementos en el interior del texto, en el lenguaje de modelización espacial, después de haber afirmado que el concepto mismo de universalidad posee, para la mayoría de las personas, un carácter claramente espacial ${ }^{8}$. Insistiremos en estos aspectos en el nivel semántico.

Decíamos que el espacio textual del hecho teatral puede dividirse en espacio diegético y espacio mimético, espacios estos que pueden coincidir, pero que generalmente son distintos.

A) Espacio textual diegético. Como espacio de la «historia», tiene características comunes con los espacios de la narrativa y de la lírica. Es el espacio (conjunto de subespacios) donde tienen lugar las acciones de la obra, tanto las que posteriormente serán representadas por los actores como aquellas que nos serán narradas, (acciones verbales).

Aparece tanto en el diálogo como en las acotaciones, y da cabida al «presente»y al «ausente» de que habla C. Pérez Gállego cuando dice que los de dentro se dedican a hablar..., pero poco a poco van apareciendo «referencias» a los ausentes, recuerdos del pasado, alusiones a frases ya dichas fuera del escenario... ${ }^{9}$

B) Espacio textual mimético. Como espacio del «discurso» presenta características propias del género literario en que se encuentra, el dramático, y aparece como un modo de selección de espacios diegéticos (o de subespacios, si se prefiere). Será, por tanto, igual o menor, como conjunto de subespacios, que el diegético, pero nunca mayor. Su función más importante es poner en relación el espacio diegético textual con el espacio escénico de la representación, y se verá de ese modo condicionado por las exigencias de este último espacio. Ha de adecuar los espacios del diegético a los requerimientos concretos del escénico, ha de modalizar el espacio de la historia para que sea viable su representación ante los espectadores en la fase espectacular.

C) Espacio espectacular escénico. Es el espacio material que aparece en el escenario, como resultado de la labor de director y de escenógrafo teatrales, quienes, más o menos fielmente, reproducen el espacio textual mimético concebido por el autor. Es la plasmación concreta que el espectador percibe visualmente en la representación; es el significante (el lugar concreto: un cuartucho, por ejemplo), cuyo significado es el espacio sugerido o simbolizado (la celda de Fausto, por ejemplo), como señala P. Pavis, para quien la metáfora y la metonimia son las dos figuras que se dan en el paso del espacio concreto al imaginado, figuras que, como demostró R. Jakobson, presiden toda significación y se-

8.- Vid. Jurij M. Lotman, Estructura del texto artistico, Madrid, Istmo (col. Fundamentos), pp. 270-271 donde cita textualmente a A. D. Aleksandrov, uespacios abstractos» en La matemática, su contenido, métodos y significación, T. III, Moscú, 1956, p. 15.

9.- Vid. Cándido Pérez Gállego, «Dentro-fuera y presente-ausente en el teatro», en J. M. Díez Borque y L. García Lorenzo (eds.), Semiología del teatro, ed. cit., p. 174. 


\section{EL ESPACIO Y EL TIEMPO TEATRALES}

miosis, y dan además la clave de todas las figuras escénicas: de su naturaleza, de su posibilidad para señalar lo real y manipular el espacio ${ }^{10}$.

D) Espacio espectacular teatral, o lugar teatral. Es el marco concreto en el que la comunicación entre el autor y el espectador tiene lugar, a través de los diversos elementos operantes en el hecho teatral, entre los que se encuentra el espacio espectacular escénico. El lugar teatral condiciona en cierto modo la plasmación del espacio escénico, el que a su vez condiciona al autor en la previsión de sus espacios textuales. La interrelación entre los cuatro espacios es constante.

$\mathrm{Al}$ ser este espacio espectacular teatral reflejo, en cierto modo, de la sociedad (su jerarquización, su mentalidad, su concepción de la comunicación teatral), ha sufrido constantemente variaciones, desde las formas semicirculares clásicas, griegas y romanas, pasando por el espacio «a la italiana», de amplia permanencia temporal, hasta las formas variadas que, de modo experimental y transitorio (sin cambios definitivos en el «lugar teatral»), se han configurado en nuestro siglo, en especial en su segunda mitad ${ }^{11}$.

En el hecho teatral, estos cuatro espacios, aislados a efectos metodológicos, se presentan en permanente interacción, sobre todo los que hemos llamado: textual mimético y espectacular escénico. Este último reproduce icónicamente al anterior en las representaciones fieles al texto y, en otras ocasiones, lo recrea indicial e incluso simbólicamente (según el planteamiento más o menos creador de director y escenógrafo teatrales). Cuanto mayor sea el distanciamiento entre ambos espacios, mayor habrá sido la labor creativa de director y escenógrafo, y mayor tendrá que ser el esfuerzo mental del espectador para la correcta percepción, intelección e interpretación del espacio escénico.

El primer punto de contacto del/de los espacio/s textual/es de la obra dramática con el espacio real (con el mundo exterior al hecho teatral del que éste se hace eco), se establece entre los espacios textual diegético y real exterior. También ahora, la relación entre el espacio textual (diegético mimético) y el espacio real exterior puede ser icónica (teatro naturalista-realista, como ejemplo máximo), indicial (incluso en el mismo teatro naturalista, basada sobre oposiciones como: exterior/interior, cerrado/abierto, arriba/abajo, etc.), y simbólica (teatro simbolista fundamentalmente, y esporádicamente en cualquier otro tipo de teatro).

El espacio textual, sirve por tanto, de enlace entre el espacio real y el espacio espectacular. Los elementos de este último actúan como signos icónicos doblemente motivados, en opinión de A. Ubersfeld, porque son elementos de la realidad (la materialidad que percibe el espectador), y a la vez se asemejan a los elementos espacializados que representan, a lo que debemos añadir una tercera iconización, puesto que son signos de signos de objetos, es decir, signo escénico (significante decía Pavis: un cuarto bien amueblado, por ejemplo), que iconiza a otro signo textual (significado en palabras de Pavis: el cuarto

10.- Vid. P. Pavis, Diccionario..., ed. cit., pp. 183-185. Cfr. Roman Jakobson, Ensayos de lingüística general, Barcelona, Seix Barral, 1981. Para una referencia de las características de los espacios teatrales de la Edad Media en España (sobre todo en Castilla), vid. Ronald E. Surtz, «El teatro en el siglo XVI (desde finales de la Edad Media a comienzos del siglo XVII)", en J. M. Díez Borque (director), Historia del Teatro en España, ed. cit. (cap. III del t. I), pp. 122-123.

11.- Cfr. M. Sito Alba, "El teatro en la Edad Media», en J. M. Díez Borque (director), Historia del Teatro en España, ed. cit., (cap. II del t. I), p. 453, donde dice refiriéndose al siglo XVI español, que paulatinamente se van mejorando las instalaciones en los locales destinados al espectáculo escénico. Así pasamos de la iglesia, plaza o salón del palacio real a los corrales de comedias... 


\section{FABIÁN GUTIÉRREZ FLÓREZ}

de la casa del personaje «x»), que a su vez iconiza a un objeto real exterior (extratextual: cualquier cuarto real y/o posible, bien amueblado) ${ }^{12}$.

El acercamiento a la categoría espacio no debe ser único en semiótica teatral: el espacio textual debe ser examinado en sus facetas, diegética y mimética, en la sintáctica, determinando sus elementos (nombres y adverbios de lugar, nombres que se refieren a espacios concretos: campo/ciudad, bosque/descampado, casa/calle, etc.); el análisis del espacio espectacular, tanto escénico como teatral, tendrá lugar en la pragmática, pues debe interesar la relación de estos espacios con el espectador y los elementos humanos que realizan la transmisión: director, escenógrafo, etc., así como la relación que mantengan los espacios escénicos y textual (paralelismo o no, según la labor de los transmisores); y por último la vinculación del espacio textual con el real exterior (su referente), deberá ser analizada en la semántica ${ }^{13}$.

\subsection{EI tiempo.}

Como hemos reiteradamente señalado en el punto anterior, espacio y tiempo se relacionan e interaccionan en el hecho teatral, tanto entre sí como con los demás elementos operantes en el teatro, sobre todo en la representación. Esta estrecha relación entre espacio y tiempo nos lleva a efectuar una división del tiempo teatral igual a la realizada en el. espacio. Hablaremos por tanto de un tiempo textual, divisible en diegético y mimético, (tiempo de la historia y del discurso respectivamente); de un tiempo espectacular, divisible en tiempo de la representación o escénico y en tiempo del espectador; y también de un tiempo exterior, extrateatral (real o posible) ${ }^{14}$.

12.- Vid. A. Ubersfeld, Lire le théâtre, ed. cit., p. 169, y P. Pavis, Diccionario..., ed. cit., pp. 182183.

13.- Existen aún otros espacios interiores, posibles objetos de consideración: el lúdico, el del director y el del actor, según opina P. Pavis, Diccionario..., ed. cit., pp. 185-187. En estas mismas páginas puede verse una tipología de los espacios escénicos, que es a la vez una tipología de las dramaturgias: A) Espacio de la tragedia griega. B) Espacio romántico (que suele sucumbir ante el oropel). C) Espacio naturalista (que imita al máximo el mundo que describe). D) Espacio simbolista (que desmantela el espacio). E) Espacio expresionista (que se modela en espacios parabólicos). Una tipología de los lugares teatrales puede verse en M. C. Carmen Bobes, Semiología de la obra..., ed. cit., pp. 251-255, donde habla de espacios en forma de T, U, D, L, M y X. Finalmente, pueden verse entre otros estudios sobre el espacio en el teatro, además de El teatro. Enciclopedia del arte escénico (Guillermo Díaz-Plaja, director), Barcelona, Noguer, 1958, y Enciclopedia dello spettacolo (S. D'Amico, comp.), Roma, Le Maschere, 1954-1968, los de J. M. Lotman, en op. cit., pp. 270282; S. Langer, Feeling and Form, Nueva York, Scribner's, 1953; AA.VV., Investigación sobre el espacio escénico, Madrid, Alberto Corazón, 1970; Allardyce Nicoll, Lo spazio scenico. Storia dell'Arte Teatrale, Roma, Bulzoni, 1971 (con numerosísimas ilustraciones); A. Morales y E. Rommer, Psychologie de l'espace, París, Lasterman, 1972; Denis Bablet, "Por une méthode d'analyse du lieu théâtral», en Travail Théâtral, 13, oct-dic., 1973; del mismo autor, Les révolutions scéniques au XXe. siècle, París, Societé Internationale d'Art XXe. siècle, 1975; Sami-Alí, El espacio imaginario, Buenos Aires, 1976; Michel Corvin "Contribution a l'analyse de l'espace scènique dans le théâtre contemporaine», en Travail Théâtral, 22, invierno 1976, pp. 62-80); S. Benmussa, "Travail de scène, travail de rêve», en Revue d'Esthetique, 1-2, 1977; M. Hays, "Theatre History and Practique: An Alternative View of Drama», en New Germane Critique, 12, 1977; y G. Banu, A. Ubersfeld y B. Piens, L'espace théâtral. Recherches dans la mise en scène d'aujourd'hui, París, C.N.R.S., 1979.

14.- Cfr. G. Bettetini, «El giro pragmático...», cit., en op. cit., pp. 24-25. Para él los textos teatrales significan temporalmente según dos modalidades: sea porque representan casi siempre un tiempo, sea porque producen sentido también a través del tiempo en sus enunciaciones. Esta división de] 


\section{EL ESPACIO Y EL TIEMPO TEATRALES}

A) Tiempo textual diegético. Es el que corresponde a la historia narrada que el texto teatral contiene, y por ello el más amplio de todos los tiempos teatrales, el de mayor duración. Textualmente nos viene dado más por el diálogo que por las acotaciones (si este tiempo existe, en la obra que se analice, de modo diferenciado con relación al mimético). Es el tiempo que incluye el de las acciones verbales (el que corresponde a las acciones narradas y a los espacios textuales diegéticos). Aparecerá marcado en el texto por los tiempos verbales sobre todo (el indefinido como tiempo caracteristico de la narración), y por otras marcas: adverbios de tiempo, etc.

Son las retrospecciones, los flash-back cinematográficos que se utilizan, lo que se presenta como específico de este tiempo teatral (al no compartir estos subtiempos con el mimético). Este procedimiento ha merecido comentarios negativos por lo que supone de negación del «ahora» propio del teatro, y por su carácter «no dramático». Sin embargo, no tendrá ește carácter per se; dependerá de su perfecta o imperfecta inserción dentro de la acción dramática, de su necesidad o de su carácter accesorio, de su oportunidad o de su inoportunidad, el que sea dramático o no dramático ${ }^{15}$.

B) Tiempo téxtual mimético. Se comporta con el diegético de manera similar a como vimos lo hacía el espacio mimético en relación con el diegético: supone una adaptación del tiempo diegético a las necesidades del género dramático, que exige la representación de un nunc ante los espectadores, aunque lo que presente sea un pasado reciente o remoto. Textualmentc sus marcas temporales aparcccrán sobrc todo $\mathrm{cn}$ las acotaciones (adverbios temporales, tiempos verbales en presente, etc.).

Incorporando el tiempo diegético en el mimético, mediante los oportunos recursos verbales narrativos sobre todo, queda conformado el tiempo textual que no es sino una previsión del tiempo espectacular ${ }^{16}$.

C) Tiempo espectacular escénico. El director y el dramaturgo (o dramaturgista, si actúa) son los encargados de elaborar y dar forma a este tiempo, tomando como base el texto mimético, y creando a la vez un tiempo que percibirá y sentirá el espectador ${ }^{17}$.

Este tiempo escénico se ha visto siempre condicionado por las costumbres y gustos sociales de cada momento histórico-literario. En la actualidad tiene una duración, en general, de dos a tres horas, el tiempo que normalmente dura la fase espectacular del hecho teatral.

tiempo en el teatro en: textual y espectacular, aparece en otros estudiosos, aunque con nombres diferentes. Cfr. M. C. Bobes Naves, Semiología de la obra..., ed. cit., pp. 217-23I (opone tiempo de la historia/tiempo del discurso, y ambos frente a tiempo espectacular); y P. Pavis, Diccionario..., ed. cit., pp. 509-514.

15.- Cfr. Lázaro Carreter, «Las damas del jueves, de Loleh Bellon», en Blanco y Negro, núm. 3.620, 13-XI-1988, p. 16, donde dice entre otras cosas sobre este recurso: «El artificio es más patente cuando el presente es más atractivo que el pasado (aunque dependa de él)». Vid. también, M. C. Bobes, Semiologia de la obra..., ed. cit., p. 220, quien opina que no es verdad que el pasado no sea dramático, sino que no puede ser representado como tal, y que será dramático en la medida que genera un presente dramático en el personaje.

16.- Cfr. A. Ubersfeld, Lire le théâtre, ed. cit., p. 225, para quien, en definitiva, la insuficiencia de los significantes temporales hace que lo esencial de los signos de la temporalidad parezca estar vinculado al modo de articulación de las unidades que cortan el texto.

17.- Cfr. Vsevolod E. Meyerhold, Teoría teatral, Caracas, Ed. Fundamentos, 1975, p. 136, donde dice que el director debe sentir el tiempo sin consultar su reloj, y que es imposible lograr un espectáculo sin poseer una aguda sensación de tiempo escénico. 
Para P. Pavis, todos los medios de expresión escénica buscan encarnar este tiempo escénico en los objetos (es decir, en un espacio) que se transforman (es únicamente en la transformación de la "praxis» donde podemos percibir el paso del tiempo) ${ }^{18}$.

D) Tiempo espectacular del espectador. Corresponde al tiempo vivido por el espectador durante la representación. Aunque en principio parece idéntico al tiempo espectacular escénico, la realidad es que sólo es idéntica la duración de ambos tiempos, como señala M. C. Bobes Naves ${ }^{19}$, y no el tiempo ni el espacio, ni la localización de una u otra categoría, por lo que esa simultaneidad de tiempos es tan convencional como la contiguidad espacial de la sala y el escenario, dado que el presente del espectador es un presente vivencial y no tiene nada que ver con el presente dramático.

Las relaciones entre los diversos tiempos enumerados son paralelas a las que mantienen los espacios en el hecho teatral. Si consideramos los tres grandes bloques temporales: tiempo exterior, tiempo textual y tiempo de la representación, vemos que también ahora el tiempo textual actúa como mediador entre los otros dos. El tiempo textual diegético vincula el hecho teatral con la realidad exterior (con su tiempo real o posible), y el tiempo mimético, una vez que modeliza dramáticamente el tiempo diégetico, se vincula directamente con el tiempo espectacular escénico.

El tiempo extratextual aparecerá iconizado en el texto dramático mediante las oportunas y diversas marcas lingüísticas (adverbios de tiempo, adjetivos, formas temporales del verbo, etc.), tanto en el diálogo como en las acotaciones. Una nueva iconización se producirá en la fase espectacular, representada para el espectador por medios verbales y no verbales (decorado, vestuario, maquillaje, etc.) que hacen referencia al paso del tiempo. A veces encontraremos indicios en lugar de iconos, y muy excepcionalmente encontraremos símbolos (salvo en hechos teatrales simbolistas).

A pesar del carácter genérico del tiempo exterior y de la complejidad del tiempo vivido por el espectador, podemos observar una gradación de los tiempos que operan en el hecho teatral, según su extensión de mayor a menor, que sería ésta: tiempo exterior, tiempo textual diegético, tiempo textual mimético, tiempo espectacular escénico y tiempo vivido por el espectador. Cada uno supone una selección del anterior, y por tanto una reducción que, de modo excepcional, puede no darse (es el caso, entre otras obras, de Madrugada, de Buero Vallejo, donde la unidad central de tiempo parece cumplirse en su plenitud, al hacer coincidir los tiempos textual y espectacular).

Pero lo que con más frecuencia encontramos en el teatro es esa selección reductiva. El tiempo textual diegético es una selección entre todos los tiempos exteriores reales o posibles; el tiempo textual mimético supone normalmente una reducción del tiempo die-

18.- Vid. P. Pavis, Diccionario..., ed. cit., p. 510, en la que también señala las técnicas más frecuentes para encarnar el paso del tiempo escénico: modificación del decorado..., etc.

19.- Vid. M. C. Bobes, Semiología de la obra..., ed. cit., pp. 233-234. Cfr. P. Pavis, Diccionario..., ed. cit., pp. 512-513, quien establece, en cambio, que la diferencia tiempo escénico/tiempo del espectador se basa en la noción bergsoniana de «duración» (de difícil manejo por su subjetividad: duración pura, duración concreta, duración realmente vivida). Para Pavis el tiempo del espectador también es distinto del del escenario, porque sólo traducimos en significados una parte de los significados escénicos de tiempo, de manera que el tiempo de la ficción, tal como lo recibimos está fragmentado y es inferior en extensión al tiempo real del espectador. Cfr. H. Bergson, Le Rire. Essai sur la signification du comique, París, 1899 (traducción española, La risa, Madrid, Prometeo, 1971). 
gético, por selección; el tiempo espectacular escénico reduce también en ocasiones el tiempo mimético que recibe del texto en la obra; y finalmente el tiempo vivido por el espectador es, en la práctica, una reducción del tiempo escénico, realizada por la selección de los momentos de este tiempo que merecen mayor atención espectatorial.

El lugar de estudio de los tiempos teatrales, dentro de nuestro modelo analítico, será (de modo semejante a como lo es para los espacios) el siguiente: determinación y relación de los elementos de los tiempos diegético y mimético (y parte de los referidos al escénico), en el apartado sintáctico semiótico; precisión del significado de esos elementos y de su relación con el tiempo exterior, en el apartado semántico semiótico; y relación de los tiempos textuales (sobre todo del mimético) con los tiempos espectaculares (sobre todo el del espectador), en el apartado pragmático semiótico teatral. Se producirá, no obstante, al igual que en el estudio de la categoría «espacio», numerosas interferencias entre los tres apartados, dado que el hecho teatral es un todo que crea un mundo propio; por ejemplo, interesa sintácticamente la detcrminación dc los clcmentos no verbales que opcran en la configuración del tiempo escénico, pero también interesan pragmáticamente esos elementos para poder comprobar cómo han sido utilizados por el director de la representación concreta que ha realizado, etc.

Puede ser interesante el análisis del modo como están modulados los tiempos textual mimético y espectacular escénico, utilizando para ello los criterios que P. Pavis propone: continuidad/discontinuidad, aceleración/ «desaceleración», concentración, obstrucción, distensión, suspensión de la imagen (repeticiones, estribillos gestuales, etc.), y reminiscencias $\left(\right.$ flash-back) ${ }^{20}$.

\subsection{Práctica analítica de espacios y de tiempos teatrales.}

\subsubsection{Sintáctica semiótica.}

Se ha precisado en puntos precedentes qué espacios y qué tiempos teatrales corresponde analizar en cada uno de los tres niveles semánticos, cuáles son las respectivas

20.- Vid. P. Pavis, Diccionario..., ed. cit., pp. 513-514. Vid también la opinión de un actor actual, José Sacristán, sobre el tiempo teatral, en su breve artículo, "Tiempo de teatro», en Suplemento semanal (de varios periódicos, El Norte de Castilla, por ejemplo), Madrid, Taller de Editores, (TESA), núm. 118, 28-I-1990, pág. 62, donde dice entre otras cosas: «En realidad, todos estamos allí por la misma sinrazón, la misma fantasía, el mismo juego: el tiempo, nuestro tiempo y por lo tanto nosotros mismos y nuestros distintos modos de entenderlo, sentirlo, disfrutarlo, padecerlo, aceptarlo, y aceptarnos o no, sencillamente». Pueden además consultarse, entre otros trabajos, sobre la categoría tiempo: S. Langer, Feeling and Form, ed. cit.; M. Descotes, Le public du théâtre et son histoire, Paris, P.U.F, 1964; Pierre Guiraud, «Temps narratif et temps dramatique: le récit dramatique», en Essais de stylistique, París, Klincksieck, 1968, pp. 151-153; P. Putz, Die Zeit im Drama, Gottingen, Vandenholck et Ruprecht, 1970; R. Demarcy, «Les modes de réception du spectacle», en Eléments d'une sociologie du spectacle, Paris, Unions Générale d'Éditions, 1973, pp. 327-406; Marco de Marinis, «L'esperienza dello spettatore», en Documenti di Lavoro, Urbino, CISL, 1974, pp. 138139); del mismo autor, «Problemas de semiótica teatral: la relación espectáculo-espectador», en Gestos, I, 1986, pp. 11-24; M. Pfister, Das Drama, Munich, Fink Verlag, 1977; M. Nojgaard, "Tempo drammatico e tempo narrativo». Saggi sui livelli temporali ne La derniere bande di Beckett», en Biblioteca teatrale, 20,1978, pp. 65-75; G. Bettetini, Tempo del senso, senso del tempo, Milán, Bompiani, 1979; Anne Marie Gourdon, Théâtre, public, perception, París, C.N.R.S., 1982; у M. Jaumain, «Théâtre et public. Approches méthodologiques de l'audience théâtrale», en Cahiers de théâtre, 49, Lovaina, 1983. 
marcas que deben ser consideradas funciones «información» de espacio y de tiempo, así como si estas se hallan en las acotaciones y/o en el texto dialogado.

Utilizaremos como ejemplo de análisis sintáctico de las categorías que nos ocupan, la obra dramática de Antonio Buero Vallejo: El tragaluz.

El espacio textual diegético de esta tragedia moderna se compone de varios subespacios: la estación de ferrocarril de una ciudad española, el salón de un semisótano de una casa de vecindad, la oficina de una editorial, el velador de un cafetín, y la calle por donde pasan y hablan los viandantes.

El espacio textual mimético elimina del diegético el subespacio de la estación. En esta obra hay además un subespacio, el de los experimentadores-narradores, que es a la vez textual diegético y mimético, e incluso espectacular escénico y teatral (al subir los actores que los representan sus papeles desde el patio de butacas).

El espacio espectacular escénico está compuesto por los subespacios que el espectador ve en la representación: un cuarto de estar pobremente amueblado, una oficina con elementos que le son propios: mesa, archivador, etc., y un velador de cafetín con mesa y sillas... La imaginación del espectador debe suplir y recomponer los otros subespacios que no se le muestran materialmente, pero que están presentes en el texto, y le son sugeridos de formas diversas (narraciones, ruido del tren, etc.,): estación de ferrocarril, subespacio de los investigadores-narradores, y subespacio exterior al tragaluz (insinuado por la presencia en un lateral de un fragmento de muro callejero, además de por las conversaciones de la gente que pasa por la calle - cuya presencia como sombras está confiada a las proyecciones-, etc.).

El espacio espectacular teatral o lugar teatral elegido para esta obra cuando se estrenó fue un local comercial con marco «a la italiana», sin duda el más adecuado en esos momentos, y pudo verse cómo dos de los personajes de la obra (los experimentadores: Él y Ella) invadían este espacio teatral; y aunque después ocupaban su sitio en el espacio escénico (un subespacio diferente al del resto de los personajes), parecía que incluso entonces no abandonaban el teatral, pues hablaban directamente a los espectadores, mientras que con el resto de los personajes no mantenían diálogo alguno.

El tiempo textual diegético de la obra dramática que hemos tomado como ejemplo para los espacios teatrales, El tragaluz, de A. Buero Vallejo, es muy amplio, pues ha de sumarse al que va desde 1936 a 1964 (el correspondiente a la historia de una familia española y del enfrentamiento entre sus miembros), el de un futuro no determinado (siglos XXV a XXX).

El tiempo textual mimético que encontramos en la tragedia bueriana es el del futuro (siglo no determinado, pero en todo cado más allá del XXIII), el correspondiente a los investigadores-narradores quienes, por una convención (juego de ilusión propuesto por el autor), invitan al espectador a situarse en ese tiempo futuro para que pueda reflexionar y juzgar objetivamente unos hechos «pasados» (vividos por la familia española citada, en la segunda mitad del siglo $\mathrm{XX}$ ), que en realidad son contemporáneos suyos.

El tiempo espectacular escénico de El tragaluz, (la noche de su estreno) fue el convencional en esos años, poco más de dos horas, durante las cuales los espectadores percibieron esos otros tiempos teatrales más extensos (los textuales). En este caso el tiempo escénico fue algo menor que el previsto en el texto, debido a la supresión de algunos fragmentos del diálogo textual, por exigencias horarias comerciales. 


\section{EL ESPACIO Y EL TIEMPO TEATRALES}

El tiempo espectacular del espectador. Ejemplificar este tiempo en la obra que venimos considerando (o en cualquier otro hecho teatral), resulta complejo y difícil en la medida que es subjetivo. Podemos pensar, con carácter general, que debido a los frecuentes momentos de "distracción" del espectador, sería este tiempo menor que el escénico. En todo caso introducidos estos condicionantes subjetivos, no puede precisarse siquiera un tiempo de "los espectadores», sino más bien una suma de los tiempos de «cada espectador» (que vivirá de manera distinta, temporalmente, el hecho teatral), lo que pragmáticamente puede ser interesante (Teoría de la recepción), a pesar de la enorme complejidad práctica que conlleva.

\subsubsection{Semántica semiótica.}

Procede en este nivel analítico, según hemos adelantado, el examen del significado de los elementos-signo de espacio y de tiempo que operen en la obra analizada, así como las relaciones que tales elementos textuales mantengan con sus correspondientes reales exteriores.

En ese análisis del significado de los signos se pueden aplicar dos enfoques: el intensional (individualizando la organización de las reglas de tales signos) y el extensional (poniéndolos en relación con aquello a que se refieren) ${ }^{2 !}$.

Si aplicamos a ambas categorías, consideradas "miméticamente», el enfoque intensional (aunque su exclusiva aplicación pueda llevar a resultados interpretativos parciales) ${ }^{22}$, podremos ver de qué forma el espacio (o los subespacios) y el tiempo (o los diversos tiempos) miméticos producen significado: si lo hacen configurando uno sólo por mera suma de sus significados parciales, o si se oponen entre ellos (subespacios por un lado y tiempos por otro).

Utilizaremos como ejemplo en este nivel semántico la primera obra dramática de Antonio Gala: Los verdes campos del Edén, cuyo espacio mimético está compuesto por varios subespacios: afueras de una ciudad, mercado de la misma, una pensión, el asilo, el cementerio, etc., y un panteón. Todos ellos pueden ser distribuidos en dos grupos que

21.- Vid. Tomás Albaladejo Mayordomo, Teoría de los mundos posibles y macroestructura narrativa. (Análisis de las novelas cortas de Clarin), Alicante, Servicio de Publicaciones de la Universidad, 1986, pp. 39-45. En las dos últimas pp. citadas, resume: «Se nos ofrece, pues, el texto como objeto que se configura respecto de dos ámbitos: el de la intensión y el de la extensión. El texto es un objeto con una dimensión cotextual, en la que está situado dicho objeto considerado en sí mismo, pero además existe en relación con el texto una dimensión contextual-extensional». Cfr. M. C. Bobes Naves, op. cit., p. 91, donde coincide con Ch. Morris en la consideración, dentro de la semántica semiótica, de la semántica de la significación/referencial (intensional/extensional en nuestra denominación), según se atienda al estudio de las relaciones de los signos con sus designata o con sus denotata respectivamente. Cfr. también Umberto Eco, Tratado de semiótica general, Barcelona, Lumen, 1985 ( $\left.3 .^{\mathrm{a}} \mathrm{ed}\right)$, pp. 117-121, en las que hablando de la teoría de la mentira, diferencia la semántica intensional (las condiciones de significación), de la semántica extensional (las condiciones de verdad).

22.- Cfr. Jonathan Culler, La poética estructuralista. El estructuralismo, la lingiüística y el estudio de la literatura, Barcelona, Anagrama, 1978, pp. 139-140, para quien el contexto que determina el significado de una oración «es algo más que las demás oraciones del texto; es un complejo de conocimientos de espectativas de distintos grados de especificidad, una especie de competencia interpretativa que en principio podría describirse, pero que en la práctica resulta extraordinariamente refractaria». 


\section{FABIÂN GUTIÉRREZ FLÓREZ}

funcionan en oposición semántica: fuera del panteón/dentro del panteón. En esta oposición resultan pertinentes las marcas: alto/bajo, exterior/interior, etc. Los subespacios de fuera se corresponden con lo que puede denominarse "preparativos para la redención»; por el contrario, el subespacio panteón es el lugar donde tienen realización las sucesivas y desiguales redenciones-liberaciones del sujeto y de sus acompañantes. Los subespacios del primer grupo no son semánticamente importantes por separado, sino como conjunto que se opone al segundo, al panteón, donde tienen lugar las acciones más importantes y trascendentales del drama, lugar que es presentado simbólicamente como espacio de tranquilidad en vida, de reposo, como espacio apto para poder llevar a cabo en él una importante misión (la contenida en el tópico o núcleo temático de este drama: la redención).

En cuanto al tiempo mimético de esta obra, vemos que se presenta destacable semánticamente como símbolo. La acción del drama tiene lugar desde finales del verano hasta el comienzo del invierno, esto es, el otoño entero y una parte muy pequeña de las dos estaciones antes ciladas. La continuidad en el paso del tiempo apenas es tenida en cuenta por el autor, pero sí presta atención al periodo estacional. Es decir, que no precisa si una acción que sucede a otra tiene lugar dos, o veinte días después, sino que lo destaca es: final del verano, día de los difuntos y nochevieja. Este período estacional tiene per se una carga semántica negativa (inclemencias climatológicas propias del otoño, incidencia directa sobre el final de la vida humana, etc.), que coincide con la simbología particular del autor, para quien estos meses tienen una carga negativa frente a la positiva que llevan los meses de la primavera-verano ${ }^{23}$.

El análisis del significado del espacio y del tiempo diegéticos (cuya base, como para los respectivos miméticos, son las «informaciones» recogidas en el nivel sitáctico semiótico), puede efectuarse desde una consideración extensional ${ }^{24}$. Así se podrá determinar la vinculación de ambos con el espacio y el tiempo reales, e incluso en el caso de los diegéticos sean históricos (cuyos referentes estarían en el pasado), la relación que tales espacio y tiempo mantienen con el ahora, con el presente histórico real.

Desde este nuevo enfoque extensional observamos en Los verdes campos del Edén, que el autor adopta un cierto "compromiso» social por medio del espacio diegético de la obra: diversas partes de una ciudad española que se está reconstruyendo, y un panteón (lugar que no es precisamente el más adecuado para realizar las acciones que en el drama se llevan a efecto, ni cualesquiera otras).

23.- Cfr. Antonio Gala. Obras escogidas, Madrid, Aguilar, 1981, edición de Fausto Díaz Padilla, pp. CXLIX-CLV, en las que al tratar de la simbología del tiempo en la obra dramática de A. Gala dice F. Díaz Padilla, entre otras cosas, que los meses con mayor carga simbólica son: a) positivos: abril, mayo, junio, julio y agosto; y b) negativos: noviembre y diciembre.

24.- El enfoque extensional es necesario y complementador del intensional en cualquier análisis semántico literario. Vid. J. M. Lotman, op. cit., pp. 262, 345 y 355 , donde considera la obra de arte literaria, y el teatro en concreto, como la reproducción de una realidad en otra, como una traducción, que tomada en sí misma, sin un determinado sistema de códigos culturales, será semejante a «un epitafio en una lengua incomprensible». Cfr. Jan Mukarovsky, «El arte como hecho semiológico», en Arte y semiología, Madrid, Alberto Corazón, 1971, p. 31, para quien el arte «es capaz de caracterizar y representar una época determinada mejor que cualquier otro fenómeno social», así como Emilio Garroni, Proyecto de semiótica, Barcelona, Gustavo Gili, 1975, p. 47, en la que, al poner en relación mundo-literatura, dice: «lo que importa, más que el reflejo mimético de la realidad, es la referencia general a la realidad, la capacidad del arte y la literatura, para interpretarla, hacerla comunicable o incluso incidir sobre ella». 


\section{EL ESPACIO Y EL TIEMPO TEATRALES}

La ciudad referenciada cs una ciudad española, por las numerosas alusiones a un país que está terminando una larga posguerra, aún pobre, en el que el sistema político imperante se caracteriza por la falta de libertades diversas, y por la presión del poder para evitar el uso de esas libertades. Los subespacios del mercado, de la pensión, de la casa del matrimonio, etc., pretenden ser el marco adecuado donde presentar un costumbrismo muy cercano a sus respectivos referentes exteriores y reales (el ambiente popular que será perfectamente identificado por el lector/espectador que lee/asiste a la representación).

El significado del tiempo diegético muestra también el compromiso de A. Gala con la sociedad, con su sociedad española de los 60 , momento en que la obra sube a escena. La acción del drama tiene lugar después de 1960 y antes de 1963 (año en que Los verdes campos..., es estrenado). En la obra tienen cabida referencias a la posguerra española y algunas alusiones, de modo inconcreto, a la propia guerra. Igualmente introduce Gala referencias concretas a la falta de libertad de expresión en la España real de entonces (inicio de la década de los 60), que entendemos como una queja dolorida del autor en nombre propio, en el del resto de los escritores, e incluso en el nombre de todos los españoles y de todos los hombres que no viven en un sistema político de libertades totales.

Terminamos este apartado semántico recordando las consideraciones de F. Lázaro Carreter sobre la posibilidad de la consecución del significado de una obra literaria en general, y sobre el modo como un espectad or teatral capta ese significado ${ }^{25}$.

\subsubsection{Pragmática semiótica.}

Procede ahora examinar el espacio y el tiempo espectaculares del hecho teatral (escénicos y teatrales/del espectador) según adelantamos.

El espacio espectacular escénico, que definíamos como el espacio material presente en el escenario que recibe el espectador, no contiene generalmente los espacios verbales, que éste debe reconstruir con su imaginación, a partir de lo que oye desde la escena.

¿Qué debe analizarse de este espacio? Primero, su acercamiento/alejamiento del espacio textual; después si la recreación de este último mejora la percepción del hecho teatral, si el trabajo del escenógrafo merece una consideración positiva o negativa, si, en definitiva, el espacio escénico aporta algo a la evolución escenográfica. Sabemos que hay algunos espacios de este tipo que mejoran el textual, que hay otros que lo destrozan, y, en fin, que existen también los que tienen validez artística por sí mismos. Habrá por tanto que determinar su relación con el texto, con la historia de las formas escenográficas, con el arte en general, y con el espectador en el momento de la recepción.

El espacio espectacular escénico de las obras de Buero Vallejo y de A. Gala que

25.- Vid. Fernando Lázaro Carreter, «Teatro y circunstancias», en Blanco y Negro, núm. 3.675, 03XI-1989, p. 14, donde después de decir que todas las obras literarias resultan de su tiempo, de las creencias y convenciones de todo tipo en cuyo seno fueron creadas, $y$ de recordar que muchos niegan que tales obras puedan ser vistas y leídas con los ojos de sus contemporáneos (sólo podría construirse un sentido por el lector o espectador actual y no reconstruir su significado), termina matizando que puede acercarse uno al significado que el autor quiso dar a la obra, upero no puede pedirse tal esfuerzo a quien asiste por diversión a una función teatral, ni aunque sea filólogo; siempre antepondrá su sentido al significado que le confió el autorm. 


\section{FABIÁN GUTIÉRREZ FLÓREZ}

venimos utilizando como ejemplos, fueron elogiados en los momentos de sus respectivos estrenos, ambos se asemejaban a las previsiones textuales, y sobre todo el de la obra bueriana suponía una muestra de la constante labor renovadora y experimental del autor ${ }^{26}$.

El espacio espectacular teatral, o lugar teatral, nunca resulta totalmente inoperante en el éxito/fracaso del hecho teatral. Desde el tipo de lugar teatral donde la obra se representa (teatro comercial, café teatro, sala particular, teatro oficial, etc.), hasta la disposición del espacio y la relación espacial entre la escena y el espectador (teatro clásico -recuérdese nuestro teatro romano de Mérida-, sala convencional a la italiana, lugar teatral adaptado en disposición circular en torno al escenario, etc.), todo puede ser objeto de consideración dentro del análisis pragmático semiótico, en la medida en que la ubicación del hecho teatral en uno de los tipos de lugar teatral mencionados, resulte significativa en la culminación dẹliproceso espectacular.

Tanto la tragedia de Buero como el drama de Gala fueron representados en sendos teatros comerciales madrileños, adecuados e importantes entre los varios que hay en la capital de España, ambos con escenario «a la italiana», sin presentar por tanto innovación alguna en este aspecto: El tragaluz lo fue en el Teatro Bellas Artes, y Los verdes campos... en el Teatro María Guerrero.

El tiempo espectacular escénico, es decir, el tiempo que dura la fase espectacular del hecho teatral, tendrá pragmáticamente interés, además de por la relación que mantenga con el tiempo textual mimético (igualdad, reducción, alargamiento, etc., respecto a éste), por la que tenga con el público que lo va a recibir. Es decir, si condicionantes comerciales y de horario (función doble), o sociales (preferencia por una función determinada: de tarde, de noche, de estreno, del lunes, etc.), inciden en su construcción.

Es frecuente que el autor dramático se vea previamente condicionado por imperativos comerciales (que se acomodan a los gustos del público), en la configuración del tiempo textual de su obra, y piense en la adecuación del tiempo escénico a esas convenciones sociales. Si ello altera la calidad, la extensión, la profundidad, o el desarrollo adecuado de la acción dramática, habrá de ser tenido en cuenta, junto con otros posibles aspectos, también extraliterarios, que en similar medida incidan sobre el tiempo escénico que se analiza.

La duración de las representaciones de las dos obras dramáticas que nos sirven de ejemplo fue semejante y acorde con las exigencias sociales y comerciales de los años de sus respectivos estrenos (1967 y 1963), si bien ha de reseñarse que en la tragedia de Buero, dada su extensión, fueron suprimidos entonces varios parlamentos y numerosos fragmentos de, otros, para conseguir mayor adecuación a las exigencias de los espectadores. Afortunadamente estas reducciones no incidieron sobre la correcta lectura de la obra. No tenemos noticia de que sucediera lo mismo con el drama de Gala, por lo que hemos

26.- Pueden verse las precisiones que sobre la elaboración de este espacio escénico de El tragahuz hace su primer director escénico, José Osuna, "Las dificultades de mi puesta en escena», en Primer Acto, núm. 90, noviembre 1967, pp. 17-18, en las que habla de la construcción de un plano inclinado con un veinte por ciento de desnivel sobre el que se movieran los personajes, del gran problema de la iluminación, y de la resolución del también problema de las proyecciones, para lo que contó con la colaboración del escenógrafo Sigfrido Burmann. En cuanto al drama de A. Gala, pueden consultarse las críticas de estreno que elogiaban tanto la dirección de José Luis Alonso y el decorado de Gago, por ejemplo las de Enrique Llovet, Francisco García Pavón y de Valencia, recogidas por Federico Carlos Sainz de Robles, Teatro español, 1963-1964, Madrid, Aguilar, 1963, pp. 183-188. 


\section{EL ESPACIO Y EL TIEMPO TEATRALES}

de entender que el propio autor previó, condicionado por las exigencias sociales, la duración del mismo.

El tiempo espectacular del espectador, de difícil precisión, como ya señalamos, transcurre parejo al escénico pero puede no coincidir con él. Suponiendo que el espectador sea puntual y asista a toda la representación, su psique le hará vivir un tiempo que, por su carácter individual, resulta extraordinariamente difícil de aislar y de valorar genéricamente. Podrá destacarse, en un análisis superficial, la impresión global que la obra produce en el espectador medio, desde el punto de vista temporal, es decir, si este tipo de espectador tiene la impresión de que la representación ha sido tan fluida que apenas ha transcurrido una hora (e incluso menos), o si por el contrario le parece que el espectáculo empezó ayer...

De El tragaluz se criticó la presencia de los personajes narradores (Él y Ella), por entender que eran innecesarios y no aportaban nada sustancial a la comprensión, ni tampoco a la emoción de la historia representada, por ser, en definitiva, generadores de «tiempos muertos» para el espectador 27.

Respecto a Los verdes campos del Edén, también la crítica periodística habló de «momentos muertos» en el espectador, porque «tardó en entrar en la obra», al desconcertar su tono nuevo ${ }^{28}$, y porque, «muy variopinto, no supo reaccionar al final de primer acto. No sabía bien de qué iba aquello», si bien en el segundo acto «entró de verdad» 29.

27.- Vid. por ejemplo la crítica de José María Quinto, «El tragaluz, de Buero Vallejo», en Ínsula, 252, diciembre 1967.

28.- Vid. Enrique Llovet, en F. C. Sainz de Robles, Teatro español, 1963-1964, ed. cit. 29.- Vid. la reseña crítica de F. García Pavón, en F. C. Sainz de Robles, Teatro español, 1963-1964, ed. cit. 